\title{
TAMANHO IDEAL DO QUADRADO DE AMOSTRAGEM PARA CARANGUEJOS CHAMA-MARÉS (OCYPODIDAE: GELASIMINAE), EM DIFERENTES FITOFISIONOMIAS DE MANGUEZAL
}

\author{
Kriegler, N. ${ }^{1,}{ }^{,}$; Santos, L.C.M. ${ }^{1,2}$ \& Pinheiro, M.A.A. ${ }^{1}$ \\ ${ }^{1}$ Universidade Estadual Paulista (UNESP), Instituto de Biociências (IB), Campus do Litoral Paulista (CLP), Programa \\ de Pós-Graduação em Biodiversidade Aquática (PPG-BA), São Vicente (SP). \\ ${ }^{2}$ Instituto Federal de São Paulo (IFSP), Campus Pirituba, São Paulo (SP). \\ *Autor correspondente: nicholaskriegler@outlook.com
}

\begin{abstract}
Os caranguejos chama-marés são excelentes modelos biológicos e fundamentais aos manguezais pela bioturbação que promovem ao sedimento. Sua densidade tem sido estimada indiretamente, pela contagem do número tocas/área. Entretanto, a ausência de um padrão de amostragem e a diversidade ambiental dos manguezais têm impedido estudos comparativos, requerendo a indicação do melhor tamanho amostral e número de réplicas para cada caso. O estudo ocorreu na ESEC Juréia-Itatins (Peruíbe, SP), em três fitofisionomias de manguezal (MA, margem; TR, transição; e AP, apicum), testando três tamanhos de quadrados $\left(0,09 \mathrm{~m}^{2}, 0,25 \mathrm{~m}^{2}\right.$ e $\left.1 \mathrm{~m}^{2}\right)$. O quadrado ideal foi indicado pelo Método de Wiegert (W), pela razão da variância relativa e custo relativo; o número mínimo de réplicas determinado na estabilização da variância (V), em função do aumento amostral; e o índice de dispersão (ID) nas fitofisionomias calculado pela relação de variância/média das tocas nos quadrados utilizados. Os animais então foram coletados e identificados. Amostras de sedimento também foram coletadas por fitofisionomia $(n=5)$, para quantificar a matéria orgânica $(M O)$. O nível de inundação pelas marés (NI) foi obtido pela altura máxima de macroalgas na base arbórea (Bostrychietum) $(\mathrm{n}=50)$. O quadrado de $0,09 \mathrm{~m}^{2}$ foi o ideal para a $M A(W=3,4)$ e AP $(W=6,9)$, com 20 réplicas, enquanto para TR foi o de $0,25 \mathrm{~m}^{2}(\mathrm{~W}=2,8)$, compreendendo 15 réplicas. A concentração de $M O$ e o $\mathrm{NI}$ decresceram no sentido $M A \rightarrow T R \rightarrow A P$, com $M O$ diferindo entre MA e AP (Dunn: $p<0,01)$ e NI contrastando entre as três fitofisionomias $(K W=52,51 ; p<0,01)$. Os resultados obtidos confirmam diferenças entre as espécies registradas nestas fitofisionomias, explicando o uso dos diferentes tamanhos amostrais. Em MA a distribuição dos caranguejos foi agregada $(I D=1,4)$ e as espécies encontradas com menor porte, repercutindo num menor quadrado amostral. A redução gradual de $\mathrm{NI}$ e MO influenciam a estrutura da vegetação e granulometria do sedimento, repercutindo na distribuição das espécies. Em TR a distribuição foi mais agregada (ID=2,6), porém diferiu quanto aos parâmetros ambientais e por espécies de maior porte, explicando o uso de um quadrado maior. Já em AP a distribuição dos chamamarés foi uniforme $(I D=0,7)$, resultando em um menor amostral. Importante destacar que os resultados obtidos possibilitam melhores informações acerca da população destas espécies, algo que é requerido, mas poucas vezes aplicado em estudos ecológicos envolvendo as espécies de Ocypodidae.
\end{abstract}

Palavras-chave: amostragem, caranguejo, dispersão, inundação, matéria orgânica. 